\title{
Modification and Application of Low and Low Temperature Economizer in Dezhou Power Plant
}

\author{
Qiudong $\mathrm{Hu}^{1 *}$ \\ ${ }^{1}$ Shandong Huayu Univeisity of Technology, Dezhou, Shandong, 253000, China
}

\begin{abstract}
At present, the exhaust gas temperature of coal-fired power plants is $125-150^{\circ} \mathrm{C}$, and the emission of high-temperature flue gas causes the loss of excess heat and wastes. For this kind of phenomenon, the waste heat recovery system is researched and designed, combined with the combination of a low-temperature economizer in a coal-fired power plant in Dezhou. The heater, through the low-temperature economizer combined with the heater system, reduces coal consumption for power generation, reduces flue gas emissions, while reducing dust specific resistance, improving dust removal efficiency of electric dust removal, and reducing dust emissions. This project responds to national policy guidelines.
\end{abstract}

\section{Introduction}

With the development of the global economy, energy and environmental protection situation, the current coal-fired power plants, especially the less economical coal-fired power plants, will face stricter environmental protection requirements and severe market operation situations. Energy conservation and emission reduction have become coal-fired two binding indicators for the development of power generation enterprises, the power dispatch of coal-fired power generation enterprises has been gradually adjusted from nameplate dispatch to energy-saving dispatch. With the increasing global environmental protection requirements, China's environmental protection standards are getting higher and higher. Most of the existing environmental protection equipment in domestic thermal power plants can no longer meet the requirements of the new emission standards and are facing a new round of environmental protection technological transformation.

The "Eleventh Five-Year Plan for Energy Development" issued by the State Council clearly stated that "building a resource-saving and environment-friendly society; insisting on equal emphasis on development and conservation, giving priority to conservation, and following the principles of reduction, reuse, and resource utilization; Vigorously promote energy-saving, water-saving, land-saving and material-saving, strengthen the comprehensive utilization of resources, improve the recycling and utilization system of renewable resources, comprehensively promote clean production, and form a low-input, low-consumption, low-emission and high-efficiency economical growth mode." This shows that energy conservation is reduced. Consumption and reduction of emissions have become two binding indicators for the production of coal-fired power generation companies.
At present, domestic flue gas waste heat recovery technology is mainly divided into four methods: condensing boiler, heat exchanger to recover flue gas waste heat, heat pump technology, and heat pipe technology. In the early flue gas waste heat recovery system, only air preheaters and economizers were installed, but the waste heat of the recovered flue gas is limited.

\section{Research status of low-temperature economizer transformation technology}

Yang Yongping [1] research shows that adding economizers and air preheaters in power plants can recover $13.3 \mathrm{MW}$ of waste heat. At present, the use of low-temperature economizers can theoretically reduce the flue gas temperature to $40 \sim 50^{\circ} \mathrm{C}$. However, subject to low-temperature corrosion, only part of the sensible heat is recovered and the exhaust gas temperature is increased. The flue gas temperature is generally above $100^{\circ} \mathrm{C}$. The waste heat recovery rate is greatly reduced, and the water consumption in the desulfurization process is also increased. In recent years, the fluoroplastic low-temperature economizer ${ }^{[2,3]}$ and heat pipe type low-temperature economizer ${ }^{[4,5]}$ have been developed in two aspects: enhancing the corrosion resistance of the heat exchange tube wall material and controlling the tube wall temperature. Reduce the impact of low-temperature corrosion on equipment, but the high production cost is an obstacle to the promotion of such equipment ${ }^{[6]}$.

Domestic scholar Wei Yiqiang et $\mathrm{al}^{[7]}$ reformed a heating boiler room in Beijing, and used absorption heat pumps in conjunction with flue gas condensation heat recovery devices to heat the entire system by using mobile phone flue gas waste heat, which greatly improved the efficiency of the boiler and reduced

*Corresponding author's e-mail: nyyjzgcxy@huayu.edu.cn 
Pollution of exhaust flue gas; Sun Fangtian et a ${ }^{[8]}$ Proposed a gas boiler flue gas waste heat recovery technical solution based on absorption heat exchange, and compared and analyzed different gas boiler heating systems from the perspective of thermodynamics, and the results showed that the technical solution It can increase the transportation capacity of the primary heating network by about $47 \%$, and the system has good economic and energy-saving benefits.

American scholar Battele Columber Labs ${ }^{[9]}$ put forward the theory of using an absorption heat pump to recover waste heat, and in 1979 the technology was applied to an absorption chiller with a refrigeration capacity of 180 tons. The use of redundant heat recovery for secondary utilization greatly reduces the energy consumption of the unit and saves costs.

Japan is the first country in the world to use waste heat for power generation. They have established a power generation system that can use flue gas as a low-temperature heat source to generate steam for power generation ${ }^{[10]}$. Japan's Boe-hman and Alam use waste heat to drive to improve the cooling efficiency of the system ${ }^{[6]}$.

In the 1990s, a coal-fired power plant in Japan developed a low-temperature coal-saving electric dust removal technology (MGGH). Compared with conventional electric dust removal technology, the low-temperature coal-saving electric dust removal technology improved the dust collection rate of the flue gas by the dust collector. The maximum can reach $30 \mathrm{mg} / \mathrm{m}^{3}$, and the volume of the dust collector is significantly smaller than the conventional dust collector, which is more convenient and has a wider application range.

During the operation of this technology, the exhaust gas temperature is reduced to about $90^{\circ} \mathrm{C}$, and due to the decrease in temperature, the $\mathrm{SO}_{3}$ generated in the flue gas is also reduced to below the acid dew point due to the effect of combustion, and then atomized and adhered to the dust in the flue gas is carried on go, increase the particle size of the fine dust in the flue gas, change the pore structure of the dust, reduce the specific resistance of the dust in the flue gas, reduce the amount of flue gas, and improve the efficiency of dust removal.

The Schwarze Pumpe power plant in Germany draws out flue gas in the flue between the desulfurization tower and the electrostatic precipitator, and installs a flue gas cooling device to recover the flue gas waste heat and use it to heat the condensate of the boiler ${ }^{[11]}$.

\section{Design of Low-temperature Economizer Cooperative Waste Heat Recovery System}

Take a certain unit of Dezhou Power Plant as an example to study the required design parameters, boiler flue gas parameters, main process parameters of low-temperature economizer, combined with the working principle and classification of boiler low-temperature economizer equipment, and adopt existing low-temperature coal-saving and heating The fan technology, design a reasonable size and carry out economic analysis, and finally achieve the purpose of energy saving, reducing unit consumption and environmental protection of coal-fired power plant boiler waste heat recovery design.

The unit's low-temperature economizer was put into operation in January 2017. The main problems of the existing low-temperature economizer are ash accumulation, wear and leakage. The first row of modules has been hard isolated, October 2018 Check and modify the low-temperature inlet deflector of the unit, and cut the 5 rows of tube bundles at the bottom of the low-level unit. The low-temperature economizer cannot be completely dredged due to the ash accumulation in the low-level module and blockage. The current low-temperature economizer is still It cannot operate normally for a long time, and there are still dust accumulation and leakage. In order to reduce the energy consumption of the unit, improve the efficiency of the dust collector, and at the same time ensure the long-term safe and stable operation of the low province, it is very necessary for the power plant to carry out the transformation of the low-temperature economizer body of the unit.

In this transformation, the existing low-temperature economizer body was removed, and the space after the removal was used to deploy a new low-temperature economizer. The layout drawing of scheme one low province is shown in figure two. The low section design size is $4840 \mathrm{~mm} \times 4400 \mathrm{~mm}$ (width $\times$ height), a set of modules are arranged along the flue gas flow direction, and the total length is $3000 \mathrm{~mm}$. A rectifying grille and a deflector are added to the low-level inlet flue to ensure the uniformity of the low-level inlet flue gas flow field. The soot blowing method adopts sonic soot blowing, which is arranged on the flue at the top of the low province. Low-temperature economizer base pipe wall temperature is higher than $70{ }^{\circ} \mathrm{C} 22$ rows of pipes are made of ND steel, and 6 rows of pipes whose pipe wall temperature is lower than $70{ }^{\circ} \mathrm{C}$ are made of $316 \mathrm{~L}$ steel. The water side inlet is improved to $316 \mathrm{~L}$ grade (6 rows), and the rest of the tube bundle is made of ND steel. Increase the horizontal and vertical pitch of the low and low tube bundles, increase the fin pitch, and adopt a single fin structure to avoid dust accumulation and adhesion bridges and blockages. Reduce the size of the low and low-cost inlet flue, and leave the denitration steel column outside the flue to avoid affecting the flue gas field. A $200 \mathrm{~mm}$ gap is reserved at the bottom of the low and low heat exchanger for dust accumulation and purge space, and the inlet part is equipped with an adjustment plate and local anti-wear tiles. 


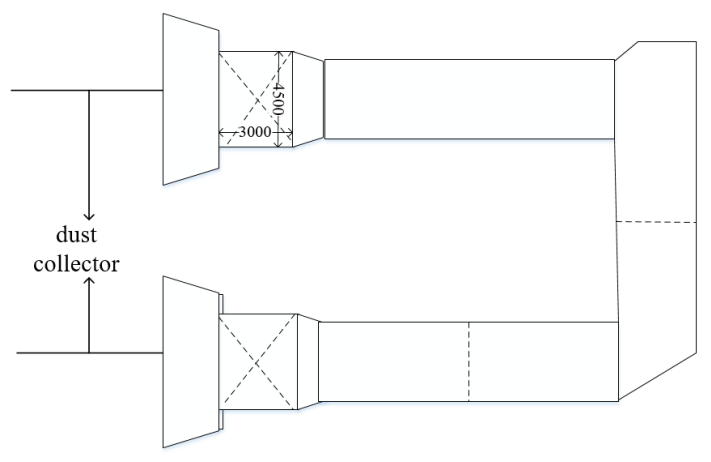

Figure 1: Low-temperature economizer floor plan

Compared with the low temperature economizer outlet flue gas temperature before and after the transformation from the original design value of $90{ }^{\circ} \mathrm{C}$ to $110{ }^{\circ} \mathrm{C}$, the outlet water temperature was reduced from the original design value of $130{ }^{\circ} \mathrm{C}$ to $95.7{ }^{\circ} \mathrm{C}$, fully reducing the heating surface body size, low temperature economizer Shift from the existing position to the inlet of the dust collector, leaving enough flue ducts for the low-level inlet. At the same time, the inlet water temperature of the low-temperature economizer is changed from $70^{\circ} \mathrm{C}$ to $65^{\circ} \mathrm{C}$, and the pipe bank with a pipe wall temperature lower than $70^{\circ} \mathrm{C}$ is made of $316 \mathrm{~L}$ material to prevent low-temperature corrosion.

A heater system and a low-temperature economizer system are added to increase the air temperature at the inlet of the air preheater to $45.0^{\circ} \mathrm{C}$ and reduce the exhaust gas temperature. As the air temperature at the inlet of the air preheater rises and the exhaust gas temperature of the boiler rises, it is calculated to rise to $169.0^{\circ} \mathrm{C}$. Therefore, the low-temperature economizer system reduces the exhaust gas temperature from a higher $169.0^{\circ} \mathrm{C}$ to $90.0^{\circ} \mathrm{C}$, which saves coal at low temperature. The waste heat of the flue gas recovered by the filter heats the condensed water.Part of the heated condensate is heated by the air heater, and the other part is sent back to the condensate system. In the design, the inlet water temperature of the low-temperature economizer is below the acid dew point, which is easy to cause low-temperature corrosion. In order to ensure the reliability of the system under all working conditions, the heating surface is made of low-temperature corrosion-resistant steel ND steel. When the inlet water temperature is low, a hot water recirculation system needs to be added to mix the outlet hot water with the inlet cold water so that the actual inlet water temperature can reach $70.0^{\circ} \mathrm{C}$ to avoid low-temperature corrosion and enhance the reliability of the system. As the exhaust gas temperature of the boiler and the inlet water temperature of the No. 6 low-pressure heater are changing, the heat absorbed by the low-temperature economizer will also continue to change. At this time, the amount of condensate extracted can be adjusted by the electric valve according to the outlet water temperature and the outlet exhaust temperature.

By reasonably arranging the flue size and heating surface structure, even if heat exchange equipment is added, the flue gas flow rate will not be too high to prevent excessive resistance; set soot blower for daily soot blowing to prevent soot accumulation; install before heating Two rows of false pipes and increase the thickness of the pipe wall on the heating surface to reduce wear; a baffle plate is installed at the entrance of the low-temperature economizer to allow the flue gas to evenly flush the heat exchange surface and enhance heat exchange efficiency; a humidity leakage detection device is arranged before and after the heating, Strictly monitor the leakage of the heating surface, once found, immediately stop the leakage or isolate the group of heating surfaces.

By reasonably arranging the flue size and heating surface structure, even if heat exchange equipment is added, the flue gas flow rate will not be too high to prevent excessive resistance; set soot blower for daily soot blowing to prevent soot accumulation; install before heating Two rows of false pipes and increase the thickness of the pipe wall on the heating surface to reduce wear; a baffle plate is installed at the entrance of the low-temperature economizer to allow the flue gas to evenly flush the heat exchange surface and enhance heat exchange efficiency; a humidity leakage detection device is arranged before and after the heating, Strictly monitor the leakage of the heating surface, once found, immediately stop the leakage or isolate the group of heating surfaces. The condensate and flue gas in the low-temperature economizer are arranged in a countercurrent arrangement. On the one hand, the heat transfer coefficient of the low-temperature economizer can be greatly improved to solve the layout crisis; on the other hand, the exhaust gas temperature can be reduced regardless of the outlet water temperature of the medium. Limits to minimize the exhaust gas temperature. The heating surface is all made of ND steel. Although the price is higher, it can greatly improve the reliability of the entire system.

The heating surfaces are arranged in groups, and each heating surface is equipped with several heat exchange tube boxes. Manual valves are installed at the inlet and outlet of each tube box, which can realize the removal and commissioning of a single tube box, which greatly improves the reliability of the system. Sex. The water intake of the low-temperature economizer is adjusted by the electric regulating valve and the outlet flue gas temperature. The detection of the wall temperature of the heating surface is very important to this system, but the detection of the wall temperature is more difficult and the accuracy is poor, so the detection of the water temperature in the heating surface is used instead of the wall temperature detection. The inlet water temperature of the heating surface is controlled above $70.0^{\circ} \mathrm{C}$. If the inlet water temperature cannot meet the requirements, the electric valve is used to adjust the water flow into the low-temperature economizer to adjust the temperature.

\section{Conclusion}

This article mainly focuses on the problem of excessively high exhaust gas temperature of coal-fired power plants causing part of the heat to be lost. Taking a power plant in Dezhou as an example, combined with the exhaust gas 
temperature before and after the transformation of low-temperature economizers, low-temperature economizers and low-temperature economizers are used. The combined technology of heaters can recover waste heat, reduce exhaust gas temperature, and reduce exhaust smoke loss. Under the condition of unchanged power generation, the energy consumption of the unit can be saved. At the same time, as the temperature of the flue gas entering the desulfurization tower decreases, the consumption of desulfurization process water can also be saved, which is in line with national policies and measures for energy conservation and emission reduction.

Therefore, the addition of a flue gas waste heat recovery device before the electrostatic precipitator can significantly reduce the amount of smoke and dust emissions, improve the atmospheric environmental quality around the power plant, and protect the health of employees. The environmental benefits are very significant.

While the flue gas waste heat recovery system has good economic efficiency, it can greatly improve the efficiency of the dust collector. Its technology is mature, the system is safe and reliable, the risk of modification is small, and the effect is obvious.

\section{Acknowledgments}

For this technology, thanks to the data support of Dezhou Power Plant, this technology has been implemented and achieved practical results.

\section{References}

1. Yang $\mathrm{Y}, \mathrm{Xu} \mathrm{C}, \mathrm{Xu} \mathrm{G}$, et al. A new conceptual cold-end design of boilers for coal-fired power plants with waste heat recovery[J].Energy Conversion and Management, 2015,89:137-146 .

2. Xu Xianggen, Chen $\mathrm{Xu}$, Zhang Chunhua. Application of non-metallic low-temperature economizer in the deep recovery of flue gas waste heat [J]. Electromechanical Information, 2016(13): 84-88.

3. Mao Shuanghua, Duo Wenming, Jiang Guoqiang, Application of fluoroplastic low-temperature economizer in waste heat recovery of flue gas from thermal power plants [J]. Chemical Production and Technology, 2015 (5): 50-52.

4. Zhao Mingxuan, Wang Changxin. The application of split heat pipe heat exchangers in the recovery of flue gas waste heat from thermal power plants [J]. Energy Conservation, 2014(1): 71-73.

5. Wang Dongfeng, Xue Zhihui. Application of enamel heat pipe type low-temperature economizer in coal-fired cogeneration [J]. Energy Research and Utilization, 2017(2): 37-39.

6. Liu Zheyi. System analysis of coal-fired flue gas waste heat recovery for central heating[D]. 2019.

7. Wei Yiqiang, Wang Suilin, Chen Kang, et al. Actual measurement and analysis of energy-saving renovation project for deep recovery and utilization of waste heat from boiler exhaust [J]. HVAC, 2013, 43 (4): 59-63.

8. Sun Fangtian, Zhao Jinzi, $\mathrm{Fu}$ Lin, et al. Energy-saving benefit analysis of gas-fired boiler flue gas waste heat recovery technology based on absorption heat exchange .[J]. Building Science, 2016 (10): 59-64.

9. Li Chensha, Liang Ji, Li Songping, et al. Recovery of industrial waste heat using absorption heat pumps [J]. Chemical Equipment Technology, 2001, 22(1): 20-26.

10. A1-Rabhghi OM,Beirutty M,Akyurt $M$, et al. Recovery and Utilization of Waste Heat[J].Heat Recovery Systems and CHP, 1993, 13 (5):463-470.

11. Long Hui, Yan Shu, Wang Dun. ntegrated design technology development of ultra supercritical unit [J]. Electric Power Construction, 2011, 32 (2):71-75. 